\title{
The effect of cupric and ferric ions on antioxidant properties of human serum albumin
}

\author{
Gholamreza Rezaei Behbehani, Katayon Gonbadi and Nasrin Eslami \\ Chemistry Department, Imam Khomeini International University, Qazvin, Iran
}

\begin{abstract}
The interaction of both ferric $\left(\mathrm{Fe}^{3+}\right)$ and cupric $\left(\mathrm{Cu}^{2+}\right)$ ions with human serum albumin (HSA) was assayed at a temperature of $27^{\circ} \mathrm{C}$ in aqueous solution using isothermal titration calorimetry. The association equilibrium constant and the molar enthalpy for one binding is $1.7 \times 10^{5} \mathrm{M}^{-1}$ and $-31.37 \mathrm{~kJ} \cdot \mathrm{M}^{-1}$, respectively. To obtain the binding parameters of metal ion-protein interaction over the whole range of $\mathrm{Fe}^{3+}$ concentrations, the extended solvation model was applied. The solvation parameters obtained from this model were attributed to the structural change of HSA. The binding parameters obtained from the extended solvation model indicate that the stability of HSA was decreased as a result of its binding with ferric ions, which cause dampening the antioxidant property of HSA. Cuperic ion increases the stability of HSA considerably, indicating that the antioxidant property of human serum albumin are increased as a result of its interaction with cupric ion.
\end{abstract}

Key words: Human serum albumin - Isothermal titration calorimetry - Ferric ion - Cupric ion

\section{Introduction}

In the presence of catalytic amounts of transition metal ions, particularly iron and copper, reactive oxygen species (ROS) can generate the highly reactive hydroxyl radical by the Fenton reaction. ROS exert their detrimental effects at least partially, through endothelial dysfunction with alterations of vascular tone, increased cell adhesion, and vascular permeability (Parola et al. 2001; Young et al. 2001; Izzet et al. 2005; Otagiri et all. 2009; Sitar et al. 2013). The high levels of ROS can result in organ damages, the ROS amount being related to the severity of sepsis and mortality. Human serum albumin (HSA) molecule acts through its multiple-binding sites against ROS free radicals and trap them. Around $70 \%$ of the free radical-trapping activity of serum was due to human serum albumin (Atukeren et al. 2010). In physiological conditions, the function associated with changes in the redox state of HSA structure and its antioxidant properties can be changed. In plasma, most of the cupric ion is bound to caeruloplasmin, but a high percentage of the metal ion may exist bound to albumin.

Correspondence to: Gholamreza Rezaei Behbehani, Chemistry Department, Imam Khomeini International University, Qazvin, Iran

E-mail: grb402003@yahoo.com
HSA contains one high affinity site for cupric ion, the Nterminal tripeptide Asp-Ala-His, indicating that cupric ion prevent oxidative damages because stabilizes HSA structure. Ceruloplasmin is an important intravascular antioxidant and it protects tunica intima against free radical injury (Bourdon et al. 2005; Papatheodorou et al. 2007; Colombo et al. 2012; Kato et al. 2014). In the present work, we have found an accurate correlation between solvation parameters obtained from the extended solvation model and antioxidant properties of HSA.

\section{Materials and Method}

HSA was obtained from Sigma-Aldrich, and $\mathrm{FeCl}_{3}$ was obtained from Merck. The buffer solution used in the experiments was $30 \mathrm{mM}$ Tris, $\mathrm{pH} 7.0$ (Merck). The isothermal titration microcalorimetric experiments were performed with the four channel commercial microcalorimetric system (Tehran University, Iran). The titration vessel was made from stainless steel. Ferric or cupric ions solution (2 mM) was injected by use of a Hamilton syringe into the calorimetric titration vessel, which contained HSA $(90.32 \mu \mathrm{M})$. Thin ( $0.15 \mathrm{~mm}$ inner diameter) stainless steel hypodermic needles, permanently fixed to the syringe, reached directly into the calorimetric vessel. Injection of iron solution into 
the perfusion vessel was repeated 29 times, with $10 \mu \mathrm{l}$ per injection. The calorimetric signal was measured by a digital voltmeter that was part of a computerized recording system. The heat of each injection was calculated by the "Thermometric Digitam 3"software program. The heat of dilution of the $\mathrm{Fe}^{3+}$ solution was measured as described above except HSA was excluded.

\section{Results and Discussion}

The calculated heats for HSA interactions with cuperic and ferric ions were shown in Figures 1 and 2.

We have shown previously that the heats of the ligand+HSA interactions in the aqueous solvent systems can be calculated via the following equation (Rezaei Behbehani et al. 2008, 2012, 2013; Barzegar et al. 2011):

$$
\begin{aligned}
& q=q_{\max } x_{B}^{\prime}-\delta_{A}^{\theta}\left(x_{A}^{\prime} L_{A}+x_{B}^{\prime} L_{B}\right)-\left(\delta_{B}^{\theta}-\delta_{A}^{\theta}\right) \\
& \left(x_{A}^{\prime} L_{A}+x_{B}^{\prime} L_{B}\right) x_{B}^{\prime}
\end{aligned}
$$

where $q$ are the heats of $\mathrm{Fe}^{3+}+\mathrm{HSA}$ interactions and $q_{\max }$ represents the heat value upon the saturation of all HSA. The parameters $\delta_{\mathrm{A}}{ }^{\theta}$ and $\delta_{\mathrm{B}}{ }^{\theta}$ are the indexes of HSA stability in the low and high cupric or ferric ion concentrations, respectively. $p>1$ or $p<1$ indicate positive or negative cooperativity of a macromolecule for binding with a ligand, respectively; $p=1$ indicates that the binding is non-cooperative. $x_{B}^{\prime}$ can be expressed as follows:

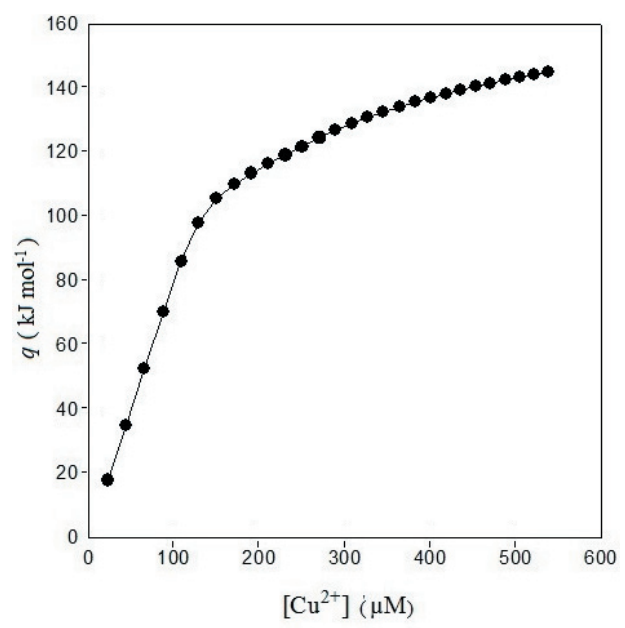

Figure 1. Comparison between the experimental heats $(\bullet)$ at $300 \mathrm{~K}$, for $\mathrm{HSA}+\mathrm{Cu}^{2+}$ interactions and the calculated data (lines) using Eq. 1. $\left[\mathrm{Cu}^{2+}\right]$, the concentrations of $\left[\mathrm{Cu}\left(\mathrm{NO}_{3}\right)_{2}\right]$ solution (the agreement between experimental and calculated data support the extended solvation model); $q$, the heat of $\mathrm{HSA}+\mathrm{Cu}^{2+}$ interaction in every concenteration of $\mathrm{Cu}^{2+}$ ion; [HSA], the concentration of human serum albumin.

$$
x_{B}^{\prime}=\frac{p x_{B}}{x_{A}+p x_{B}}
$$

We can express $x_{B}$ fractions, as the total $\mathrm{Fe}^{3+}$ concentrations divided by the maximum concentration of the $\mathrm{Fe}^{3+}$ upon the saturation of all HSA as follows:

$$
x_{B}=\frac{\left[F e^{3+}\right]}{\left[F e^{3+}\right]_{\max }}, \quad x_{A}=1-x_{B}
$$

where $\left[\mathrm{Fe}^{3+}\right]$ is the concentration of $\mathrm{Fe}^{3+}$ ions after every injection and $\left[\mathrm{Fe}^{3+}\right]_{\max }$ is the maximum concentration of the $\mathrm{Fe}^{3+}$ ions upon the saturation of all HSA. $L_{\mathrm{A}}$ and $L_{\mathrm{B}}$ are the relative contributions due to the fractions of unbound and bound metal ions in the heats of dilution in the absence of HSA and can be calculated from the heats of dilution of $\mathrm{Fe}^{3+}$ ions in buffers, $q_{\text {dilut }}$, as follows:

$$
L_{A}=q_{\text {dilut }}+x_{B}\left(\frac{\partial q_{\text {dilut }}}{\partial x_{B}}\right), L_{B}=q_{\text {dilut }}+x_{A}\left(\frac{\partial q_{\text {dilut }}}{\partial x_{B}}\right)
$$

The heats of $\mathrm{Fe}^{3+}+\mathrm{HSA}$ interactions, $q$, were fitted to Eq. 1 across the whole $\mathrm{Fe}^{3+}$ compositions. In the fitting procedure, the only adjustable parameter $(p)$ was changed until the best agreement between the experimental and calculated data was approached (Fig. 1). The $\delta_{\mathrm{A}}{ }^{\theta}$ and $\delta_{\mathrm{B}}{ }^{\theta}$ values are recovered from the coefficients of the second and third terms of Eq. 1. The small relative standard coefficient errors and the high $\mathrm{r}^{2}$

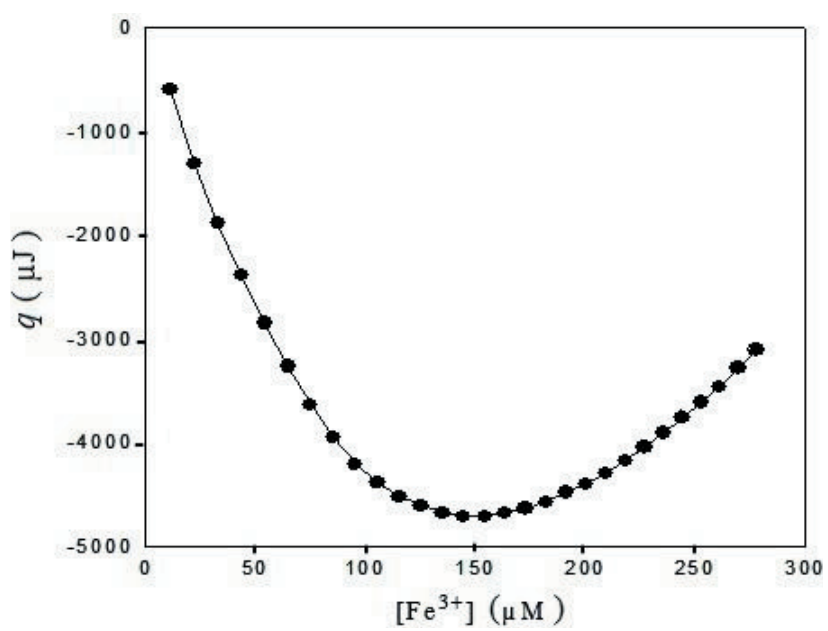

Figure 2. Comparison between the experimental heats $(\bullet)$ at $300 \mathrm{~K}$, for $\mathrm{Fe}^{3+}+\mathrm{HSA}$ interactions and the calculated data (lines) using Eq. 1. $\left[\mathrm{Fe}^{3+}\right]$, the concentrations of $\left[\mathrm{FeCl}_{3}\right]$ solution (the agreement between experimental and calculated data support the validity of Eq. 1); $q$, the heat of $\mathrm{HSA}+\mathrm{Fe}^{3+}$ interaction in every concenteration of $\mathrm{Fe}^{3+}$ ion; [HSA], the concentration of human serum albumin. 
values (0.99999) support the method. The binding parameters for $\mathrm{Fe}^{3+}+\mathrm{HSA}$ and $\mathrm{Cu}^{2+}+\mathrm{HSA}$ interactions obtained from Eq. 1 were listed in Table 1. The agreement between the calculated and experimental results (Fig. 2) is striking, and gives considerable support to the use of Eq. $1 . \delta_{\mathrm{A}}{ }^{\theta}$ and $\delta_{\mathrm{B}}{ }^{\theta}$ values for $\mathrm{Fe}^{3+}+\mathrm{HSA}$ interactions is negative, indicating that in the low and high concentrations of the metal ions the HSA structure is destabilized, resulting in a decrease in its antioxidant properties of HSA (Table 1).

The more stable HSA can trap the free radical and decrease the oxidative stress. In the other hand, we can predict the stability of HSA accurately using Eq. 1 and attribute $\delta_{\mathrm{A}}{ }^{\theta}$ and $\delta_{\mathrm{B}}{ }^{\theta}$ values to the antioxidant properties of HSA. Cuperic ions in solution interact strongly with human serum albumin as indicated by the large and positive $\delta_{\mathrm{A}}{ }^{\theta}$ and $\delta_{\mathrm{B}}{ }^{\theta}$ values (Table 1 ) and stabilized the HSA structure significantly. In other words, the stabilities indexes $\left(\delta_{\mathrm{A}}{ }^{\theta}\right.$ and $\delta_{\mathrm{B}}{ }^{\theta}$ values), calculated from Eq. 1 for $\mathrm{HSA}+\mathrm{Cu}^{2+}$ interactions is considerably positive, indicating that in the low and high concentrations of the $\mathrm{Cu}^{2+}$ ions, the HSA structure is stabilized drastically. The $\delta_{\mathrm{A}}{ }^{\theta}$ and $\delta_{\mathrm{B}}{ }^{\theta}$ values for $\mathrm{HSA}+\mathrm{Fe}^{3+}$ interactions are negative (unstable $\mathrm{HSA}+\mathrm{Fe}^{3+}$ complex), showing that the trace amounts of ferric ion can decrease the antioxidant property of HSA and increase oxidative stress. $\mathrm{HSA}+\mathrm{Cu}^{2+}$ complex is much more stable than $\mathrm{HSA}+\mathrm{Fe}^{3+}$ complex, resulting in a great increase of antioxidant activity of HSA as a result of its interation with cupric ions. The large and positive $\delta_{\mathrm{A}}{ }^{\theta}$ and $\delta_{\mathrm{B}}{ }^{\theta}$ values show that the high stable $\mathrm{HSA}+\mathrm{Cu}^{2+}$ complex has a strong tendency against the free radicals and prevent a subsequent Fenton reaction to produce the most harmful of hydroxyl radical $\left({ }^{\circ} \mathrm{OH}\right)$, which prevent to the development of several age-related diseases by inducing oxidative damage.

For a set of identical and independent binding sites, according to the recent data analysis method, using Eq. 5, a plot of $\left(\frac{\Delta q}{q_{\max }}\right) M_{0}$ versus $\left(\frac{\Delta q}{q}\right) L_{0}$ should be a linear plot by a slope of $1 / \mathrm{g}$ and the vertical-intercept of $\frac{K_{d}}{g}$, g and $K_{d}$ can be obtained (Rezaei Behbehani et al. 2008, 2012, 2013; Barzegar et al. 2011)

$$
\frac{\Delta q}{q_{\max }} M_{0}=\left(\frac{\Delta q}{q}\right) L_{0} \frac{1}{g}-\frac{K_{d}}{g}
$$

where $\mathrm{g}$ is the number of binding sites, $K_{d}$ is the dissociation equilibrium constant, $M_{0}$ and $L_{0}$ are concentrations of biomacromolecule and ligand, respectively, $\Delta q=q_{\max }-q$, $q$ represents the heat value in the certain metal ions concenteration and $q_{\max }$ represents the heat value upon the saturation of all HSA. If $q$ and $q_{\max }$ are calculated per mole of biomacromolecule then the molar enthalpy of binding for
Table 1. Binding parameters for $\mathrm{HSA}+\mathrm{Fe}^{3+}$ and $\mathrm{HSA}+\mathrm{Cu}^{2+}$ interactions

\begin{tabular}{lcc}
\hline parameters & $\mathrm{HSA}^{2} \mathrm{Fe}^{3+}$ & $\mathrm{HSA}+\mathrm{Cu}^{2+}$ \\
\hline$p$ & $1 \pm 0.01$ & $1 \pm 0.01$ \\
$\delta^{\theta}{ }_{\mathrm{A}}$ & $-2.98 \pm 0.14$ & $59.06 \pm 0.18$ \\
$\delta^{\theta}{ }_{\mathrm{B}}$ & $-6.73 \pm 0.17$ & $58.34 \pm 0.19$ \\
$K_{a} / \mathrm{M}^{-1}$ & $(3.7 \pm 0.032) \times 10^{5}$ & $(3.7 \pm 0.021) \times 10^{5}$ \\
$\Delta H(\mathrm{~kJ} / \mathrm{mol})$ & $-31.79 \pm 0.07$ & $-33.51 \pm 0.09$ \\
$\Delta G(\mathrm{~kJ} / \mathrm{mol})$ & $-31.97 \pm 0.06$ & $-30.05 \pm 0.09$ \\
$\Delta S(\mathrm{~kJ} / \mathrm{mol} \cdot \mathrm{K})$ & $0.0006 \pm 0.00001$ & $-0.01 \pm 0.002$ \\
\hline
\end{tabular}

The negative values of $\delta_{A}^{\theta}$ and $\delta_{B}^{\theta}$ indicate that the ferric ion dampened antioxidant activity of HSA. Positive and large $\delta_{A}^{\theta}$ and $\delta_{B}^{\theta}$ values indicate that $\mathrm{Cu}^{2+}$ ion stabilizes the HSA structure significantly and increases the antioxidant properties of HSA. $p$, cooperativity index; $\delta_{\mathrm{A}}^{\theta}$ and $\delta_{\mathrm{A}}^{\theta}$ the structural changes of HAS indexes; $\Delta \mathrm{H}$, enthalpies of $\mathrm{HSA}+\mathrm{Fe}^{3+}$ and $\mathrm{HSA}+\mathrm{Cu}^{2+}$ and interactions; $\Delta \mathrm{G}$, free energies of $\mathrm{HSA}+\mathrm{Fe}^{3+}$ and $\mathrm{HSA}+\mathrm{Cu}^{2+}$ interactions; $\Delta \mathrm{S}$, entropies of the interactions.

each binding site $(g)$ will be $\Delta \mathrm{H}=\mathrm{q}_{\max } / g$. The related plot for the binding of Iron ions by HSA is shown in Figure 3.

To compare all thermodynamic parameters in metal binding process for HSA, the change in standard Gibbs free energy $(\Delta G)$ should be calculated according to the Eq. 6 , which its value can use in Eq. 7 for calculating the change in standard entropy $(\Delta S)$ of the binding process.

$$
\begin{aligned}
& \Delta G^{\circ}=-R T \ln K_{a} \\
& \Delta G^{\circ}=\Delta H^{\circ}-T \Delta S^{\circ}
\end{aligned}
$$

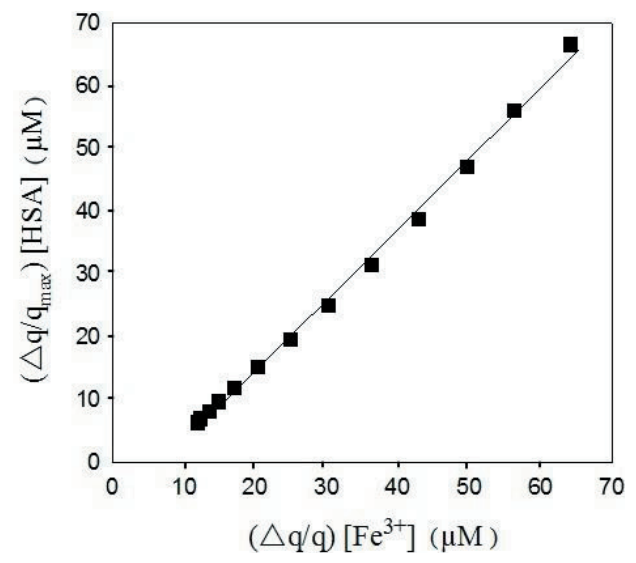

Figure 3. A representation of approaching to the best linear plot of $\left(\frac{\Delta q}{q_{\max }}\right)[H S A](-)$ against $\left(\frac{\Delta q}{q}\right)\left[F e^{3+}\right]$, using $q_{\text {max }}=-5100 \mu \mathrm{J}$ at $\mathrm{T}=300 \mathrm{~K}$ for $\mathrm{HSA}+\mathrm{Fe}^{3+}$ interaction. [HSA], the concentration of human serum albumin. 
where $K_{a}$ is the association binding constant (the inverse of the dissociation binding constant, $K_{d}$ ). The thermodynamic parameters were listed in Table 1.

\section{Conclusion}

The solvation parameters obtained from the extended solvation model (Eq. 1) model were attributed to the structural change of HSA. The more stable HSA can trap the free radical and decrease the oxidative stress. In the other hand, the stability of HSA is predicted simply using Eq. 1, therby, $\delta_{A}{ }^{\theta}$ and $\delta_{\mathrm{B}}{ }^{\theta}$ values can be correlated to the antioxidant properties of HSA. $\delta_{\mathrm{A}}{ }^{\theta}$ and $\delta_{\mathrm{B}}{ }^{\theta}$ values for $\mathrm{Fe}^{3+}+\mathrm{HSA}$ interactions is negative, indicating that in the low and high concentrations of the feric ions, the HSA structure is destabilized, which dampened the antioxidant property of HSA. The large and positive $\delta_{\mathrm{A}}{ }^{\theta}$ and $\delta_{\mathrm{B}}{ }^{\theta}$ values show that the high stable $\mathrm{HSA}+\mathrm{Cu}^{2+}$ complex has a strong tendency against the free radicals formation, resulting in a great increase of antioxidant property of HSA as a result of its interation with cupric ions.

\section{References}

Atukeren P., Aydin S., Uslu E., Gumustas M. K., Cakatay U. (2010): Redox homeostasis of albumin in relation to alpha-lipoic acid and dihydrolipoic acid. Oxid. Med. Cell Longev. 3, 206-213 http://dx.doi.org/10.4161/oxim.3.3.11786

Barzegar L., Rezaei Behbehani G., Saboury A. A. (2011): A thermodynamic study of zinc ion interaction with bovin carbinic anhydrase II at different temperatures. J. Solution Chem. 40, 843-848 http://dx.doi.org/10.1007/s10953-011-9686-2

Bourdon E., Loreau N., Lagrost L., Blache D. (2005): Differential effects of cysteine and methionine residues in the antioxidant activity of human serum albumin. Free Radic. Res. 39, $15-20$ http://dx.doi.org/10.1080/10715760400024935

Colombo G., Clerici M., Giustarini D., Rossi R., Milzani A., DalleDonne I. (2012): Redox albuminomics: oxidized albumin in human diseases. Antioxid. Redox. Signal. 17, 1515-1527 http://dx.doi.org/10.1089/ars.2012.4702
Izzet T., Osman K., Ethem U., Nihat Y., Ramazan K., Mustafa D., Hafize U., Riza K. A., Birsen A., Habibe G., Seval A., Gonul S. (2005): Oxidative stress in portal hypertension-induced rats with particular emphasis on nitric oxide and trace metals. World J. Gastroenterol. 11, 3570-3573

Kato R., Akiyama M., Kawakami H, Komatsu T. (2014): Superoxide dismutase activity of the naturally occurring human serum albumin-copper complex without hydroxyl radical formation. Chem. Asian J. 9, 83-86 http://dx.doi.org/10.1002/asia.201301285

Otagiri M., Chuang V. T. (2009): Pharmaceutically important preand posttranslational modifications on human serum albumin. Biol. Pharm. Bull. 32, 527-534 http://dx.doi.org/10.1248/bpb.32.527

Papatheodorou L., Weiss N. (2007): Vascular oxidant stress and inflammation in hyperhomocysteinemia. Antioxid. Redox. Signal. 9, 1941-1958 http://dx.doi.org/10.1089/ars.2007.1750

Parola M., Robino G. (2001): Oxidative stress-related molecules and liver fibrosis. J. Hepatol. 35, 297-306 http://dx.doi.org/10.1016/S0168-8278(01)00142-8

Rezaei Behbehania G., Saboury A.A., Taleshi E. (2008): Determination of partial unfolding enthalpy for lysozyme upon interaction with dodecyltrimethylammonium bromide using an extended solvation model. J. Mol. Recognit. 21, 132-135 http://dx.doi.org/10.1002/jmr.881

Rezaei Behbehani G., Mirzaie M., Mehreshtiagh M., Barzegar L., Saboury A. A., Mohammadi Gorgi S. (2012): Inhibitory effects of p-phenylene-bis and phenyl dithiocarbamate on mushroom tyrosinase J. Solution Chem. 41, 581-588 http://dx.doi.org/10.1007/s10953-012-9821-8

Rezaei Behbehani G., Mehreshtiagh M., Barzegar L., Saboury A. A. (2013): A calorimetric investigation for the bindings of mushroom tyrosinase to p-phenylene-bis dithiocarbamate and xanthates. J. Serb. Chem. Soc. 78, 255-263

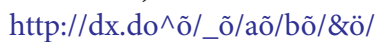

Sitar M. E., Aydin S., Cakatay U. (2013): Human serum albumin and its relation with oxidative stress. Lab. 59, 945-952

Young I. S., Woodside J. V. (2001): Antioxidants in health and disease. J. Clin. Pathol. 54, 176-186

http://dx.doi.org/10.1136/jcp.54.3.176

Received: February 11, 2014

Final version accepted: April 28, 2014

First published online: August 22, 2014 